\title{
GABA Uptake via GABA Transporter-1 Modulates GABAergic Transmission in the Immature Hippocampus
}

\author{
Sampsa Sipilä, Kristiina Huttu, Juha Voipio, and Kai Kaila \\ Department of Biological and Environmental Sciences, University of Helsinki, FIN-00014 Helsinki, Finland
}

GABA uptake limits GABA actions during synaptic responses when the density of active release sites is high or multiple axons are synchronously activated. GABA transporter-1 (GAT-1) is the main neuronal GABA transporter subtype and is already expressed in the early postnatal rat hippocampus. However, previous studies have demonstrated little functional role for the transporter during this developmental period. We used whole-cell voltage-clamp and field-potential recordings in hippocampal slices of neonatal rats (postnatal day 4-5) to study whether GAT-1 plays a role in GABAergic transmission during spontaneous population oscillations, which are seen as "giant depolarizing potentials" (GDPs) in intracellular recordings. We show that the GDP-associated GABAergic current observed in CA3 pyramidal neurons is strongly enhanced by the GAT-1-specific blocker NO-711 (1-[2-[[(diphenylmethylene)imino]oxy]ethyl]-1,2,5,6tetrahydro-3-pyridinecarboxylic acid hydrochloride). Our results indicate a novel role for GAT-1 in the control of endogenous activity of the immature hippocampus.

Key words: GAT-1; development; hippocampus; network; activity; GDP

\section{Introduction}

$\mathrm{Na}^{+}$-dependent uptake regulates the ambient level of GABA in the interstitial space in brain tissue (Frahm et al., 2001; Nusser and Mody, 2002; Semyanov et al., 2003). In the mature brain, blocking GABA uptake pharmacologically (Thompson and Gähwiler, 1992) or by genetically disrupting the expression of GABA transporter-1 (GAT-1) (Jensen et al., 2003) has little effect on spontaneous $\mathrm{GABA}_{\mathrm{A}}$-mediated IPSCs (sIPSCs) or miniature $\mathrm{GABA}_{\mathrm{A}}$-mediated IPSCs (Nusser and Mody, 2002; Overstreet and Westbrook, 2003). However, where the density of active release sites is high, unitary IPSCs elicited by single presynaptic action potentials are prolonged (Overstreet and Westbrook, 2003). Moreover, evoked IPSCs as a result of stimulation of multiple axons and consequent GABA spillover are limited by cellular uptake (Thompson and Gähwiler, 1992; Isaacson et al., 1993; Roepstorff and Lambert, 1994).

GAT-1 is the main neuronal GABA-transporter subtype (Guastella et al., 1990) and is abundant in presynaptic GABAergic terminals (Minelli et al., 1995). Although it is expressed already at birth (Yan et al., 1997; Frahm and Draguhn, 2001), there is little evidence for any functional role for GAT-1 in neuronal signaling during the early postnatal period in the rat hippocampus (Draguhn and Heinemann, 1996; Caillard et al., 1998; Sabau et al., 1999; Demarque et al., 2002).

A salient feature of endogenous neuronal activity in the immature hippocampus is the presence of spontaneous population

\footnotetext{
Received April 6, 2004; revised May 13, 2004; accepted May 15, 2004. This work was supported by the Academy of Finland and by the Sigrid Juselius Foundation.

Correspondence should be addressed to Kai Kaila, Department of Biosciences, University of Helsinki, P.0. Box 65 (Viikinkaari 1), FIN-00014 Helsinki, Finland. E-mail: Kai.Kaila@Helsinki.Fi.

DOI:10.1523/JNEUROSCI.1287-04.2004

Copyright $\odot 2004$ Society for Neuroscience $\quad$ 0270-6474/04/245877-04\$15.00/0
}

oscillations, which were originally observed in intracellular voltage recordings in pyramidal neurons and termed "giant depolarizing potentials” (GDPs) (Ben-Ari et al., 1989; Leinekugel et al., 2002). This type of synchronous network event is thought to be involved in the maturation of neuronal circuits (Feller, 1999; Penn and Shatz, 1999; Katz and Crowley, 2002). In this work, we show that although it has no or very little effect on single sIPSCs in early postnatal hippocampal slices, blocking GAT-1 leads to a marked enhancement of $\mathrm{GABA}_{\mathrm{A}}$ receptor $\left(\mathrm{GABA}_{\mathrm{A}} \mathrm{R}\right)$-mediated transmission during GDPs.

\section{Materials and Methods}

Postnatal day 4-5 Wistar rat pups were decapitated, and brains were quickly removed and dissected in cold $\left(0-4^{\circ} \mathrm{C}\right)$, oxygenated $(95 \%$ $\mathrm{O}_{2}-5 \% \mathrm{CO}_{2}$ ) standard solution, containing (in $\mathrm{mm}$ ): $124 \mathrm{NaCl}, 3.0 \mathrm{KCl}$, 2.0 $\mathrm{CaCl}_{2}, 25 \mathrm{NaHCO}_{3}, 1.1 \mathrm{NaH}_{2} \mathrm{PO}_{4}, 1.3 \mathrm{MgSO}_{4}$, and 10 D-glucose, $\mathrm{pH}$ 7.4 at $32^{\circ} \mathrm{C}$. For whole-cell recordings, coronal brain slices $(350 \mu \mathrm{m})$ were cut with a vibrating blade microtome (VT1000S; Leica, Nussloch, Germany), bisected into two hemispheric components, and allowed to recover for at least $1 \mathrm{hr}$ at $32^{\circ} \mathrm{C}$ before use.

Individual slices were transferred into a submersion-type recording chamber, perfused (rate, $3-4 \mathrm{ml} / \mathrm{min}$ ) with oxygenated $\left(32-33^{\circ} \mathrm{C}\right)$ standard solution, and anchored with platinum wires on the bottom of the chamber. Axopatch 200B (Axon Instruments, Union City, CA) and EPC-10 (HEKA Elektronik, Lambrecht, Germany) amplifiers were used for voltage-clamp recordings in whole-cell mode. Patch pipettes had resistances of 5-7 M $\Omega$ when filled with (in $\mathrm{mM}$ ): 140 Csmethanesulfonate, $2 \mathrm{MgCl}_{2}$, and 10 HEPES, pH 7.2 with CsOH. Series resistance and whole-cell capacitance were estimated by compensating for the fast current transients associated with $5-10 \mathrm{msec}, 5 \mathrm{mV}$ voltage steps. Series resistance $[15.6 \pm 0.9 \mathrm{M} \Omega($ mean \pm SEM) $]$ was left uncompensated or was compensated by $60-70 \%$ with a lag of $6-9 \mu \mathrm{sec}$. In voltage-clamp recordings, the holding potential was $0 \mathrm{mV}$ when corrected using a calculated $13 \mathrm{mV}$ liquid junction potential. Assuming a 0.3 permeability ratio for bicarbonate versus $\mathrm{Cl}^{-}$, the calculated reversal 
potential of $\mathrm{GABA}_{\mathrm{A}} \mathrm{R}$-mediated responses $\left(E_{\mathrm{GABA}-\mathrm{A}}\right)$ is approximately $-75 \mathrm{mV}$ under the present conditions (Kaila et al., 1993). Using infrared video microscopy (Stuart et al., 1993), CA3 pyramidal neurons were selected for recordings on the basis of the orientation of soma in the pyramidal layer and with the apical dendrite pointing toward the stratum lucidum. A bipolar electrode was placed in the stratum lucidum at a distance of $100-300 \mu \mathrm{m}$ from the recording site to deliver stimuli (100 $\mu \mathrm{sec}, 15-50 \mathrm{~V})$ in trains $(9-30$ pulses, $10 \mathrm{~Hz})$ at $90 \mathrm{sec}$ intervals. Fieldpotential (fp) recordings were performed with a glass capillary electrode (tip diameter, $\sim 10 \mu \mathrm{m}$ ) filled with $150 \mathrm{~mm} \mathrm{NaCl}$.

2,3-Dihydroxy-6-nitro-7-sulfonyl-benzo[f]quinoxaline (NBQX), D,LAP-5, (2S)-3-\{[(15)-1-(3,4-dichlorophenyl)ethyl]amino-2-hydroxypropyl $\}$ (phenylmethyl)phosphinic acid (CGP), tetrodotoxin (TTX), and bicuculline methobromide (bic) were from Tocris Cookson (Bristol, UK). 1-[2-[[(diphenylmethylene)imino] oxy] ethyl]-1,2,5,6-tetrahydro-3pyridinecarboxylic acid hydrochloride (NO-711) was from Sigma (St. Louis, MO).

Data were stored on tape and low-pass filtered at $2 \mathrm{kHz}$ before digitization at $5 \mathrm{kHz}$ for analyses with Clampfit 8.0 (Axon Instruments) and Strathclyde Electrophysiology Windows Whole Cell Program and Windows Electrophysiology Disk Recorder (WinEDR) (Dr. John Dempster, University of Strathclyde, Glasgow, UK) programs. For analysis of spontaneous IPSCs, events during inter-GDP intervals with a peak amplitude of $>6 \mathrm{pA}$ were detected with an algorithm in WinEDR (Strathclyde Electrophysiology Software). sIPSCs that appeared to consist of more than one event were rejected. These amounted to $\sim 35 \%$ of the total number originally detected, with no significant difference between control and NO-711 application. For averaging, signals were aligned by the rising phase. Averaged sIPSCs were fitted with two exponential functions, and weighted decay time constants $(\tau)$ were calculated using the equation $\tau=A_{1} \tau_{1}+A_{2} \tau_{2}$, where $A_{\mathrm{i}}$ is the relative amplitude and $\tau_{\mathrm{i}}$ is the time constant of each component (Overstreet and Westbrook, 2003). The fp GDPs were aligned by the onset of the fast negative phase for averaging. Data are expressed as mean \pm SEM. Quantitative comparisons were based on paired Student's $t$ tests, for which $p$ values of $<0.05$ were considered to be statistically significant.

\section{Results}

A stimulus train protocol (9 pulses, $10 \mathrm{~Hz}$ ) was used to trigger synchronous firing of interneurons and to promote synaptic release of GABA. NBQX (10 $\mu \mathrm{M})$, D,L-AP-5 (40 $\mu \mathrm{M})$, and CGP (1 $\mu \mathrm{M})$ were applied to exclude effects involving ionotropic glutamate and $\mathrm{GABA}_{\mathrm{B}}$ receptors. The cells were clamped at a holding potential of $0 \mathrm{mV}$, whereas calculated $E_{\mathrm{GABA}-\mathrm{A}}$ is approximately $-75 \mathrm{mV}$ (see Materials and Methods). In addition to IPSCs triggered by individual stimulus pulses, the train of stimuli induced a gradually increasing, outwardly directed baseline current followed by a slow decay (Fig. $1 \mathrm{~A}$ ). The mean time of decay to $30 \%$ from the instantaneous level of the slow current at the time of the last stimulus was $630 \pm 130 \mathrm{msec}$. The mean total charge transfer after the last pulse in the stimulus train was $47 \pm 20 \mathrm{pC}(n=6)$. The train-evoked slow outward current was greatly enhanced by bath application of the GAT-1-specific inhibitor NO-711 (2.5 $\mu \mathrm{M})$, with its duration increasing to $350 \pm 40 \%(p=0.0015)$ and total charge transfer increasing to $260 \pm 59 \%(p=0.044)$ from the control value $(n=6)$ (Fig. $1 A, B)$. The IPSCs and the slow outward current were blocked by $10 \mu \mathrm{M}$ bicuculline, confirming that both were mediated by $\mathrm{GABA}_{\mathrm{A}}$ receptors $(n=3)$ (Fig. $\left.1 A\right)$. Additional experiments were performed in extracellular solution containing $0.5 \mathrm{mM} \mathrm{Ca}^{2+}$ and $5 \mathrm{~mm} \mathrm{Mg}^{2+}$ (Berry and Pentreath, $1976)$ in the presence of the glutamate- and $\mathrm{GABA}_{\mathrm{B}}$-receptor blockers to reduce possible self-sustaining excitatory effects within the interneuronal network. However, a train of stimuli (30 pulses, $10 \mathrm{~Hz}$ ) again induced a current that was prolonged by bath application of $2.5 \mu \mathrm{M}$ NO-711 (Fig. 1C). A $1 \mu \mathrm{M}$ concentration of TTX blocked the stimulus-induced currents $(n=3)$, in-

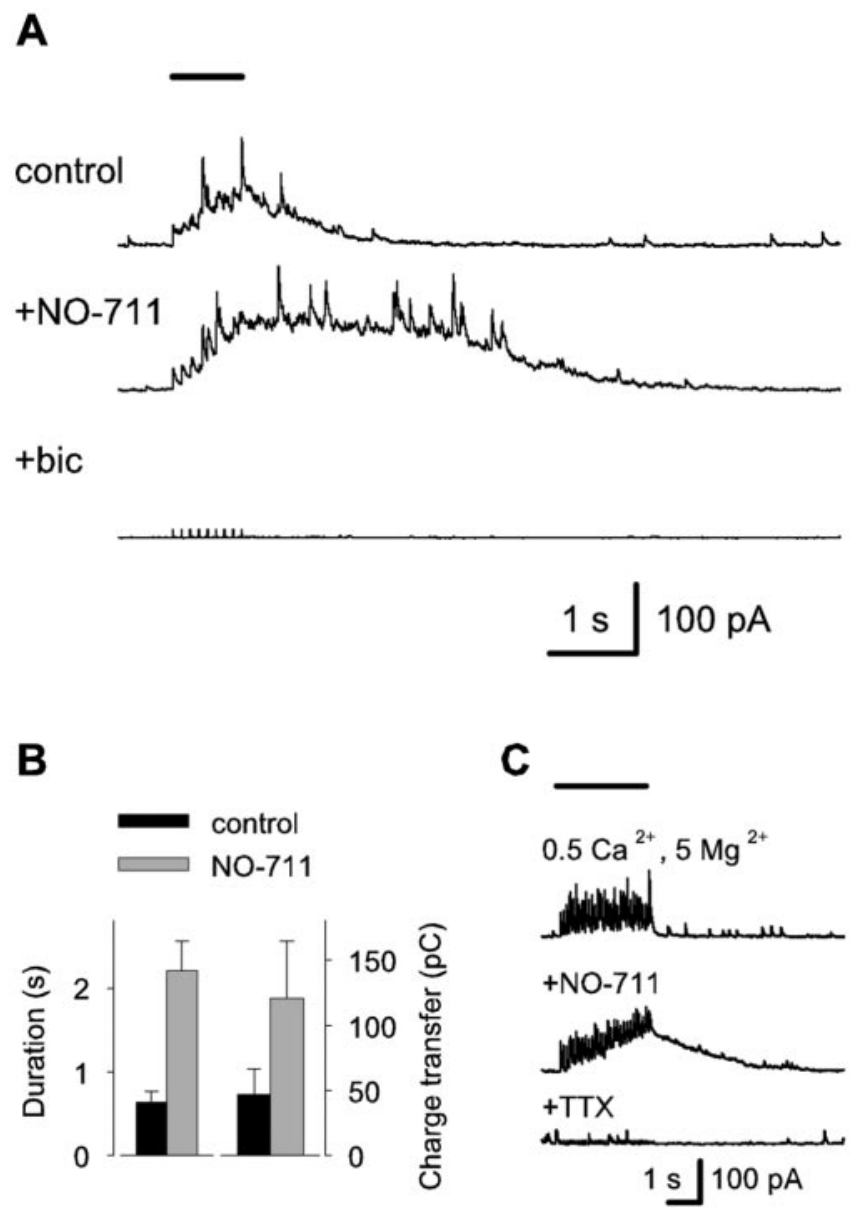

Figure 1. Blocking GAT-1 enhances stimulus train-induced slow $G A B A_{A} R$-mediated currents in neonatal CA3 neurons. $A$, Specimen voltage-clamp recordings at a holding potential of $0 \mathrm{mV}$ with a low chloride pipette filling solution showing currents evoked by a train of stimuli ( 9 pulses, $10 \mathrm{~Hz}$ ) indicated by the horizontal bar shown at the top (stimulus artifacts are truncated). All recordings were done in the presence of $10 \mu \mathrm{M} \mathrm{NBQX}, 40 \mu \mathrm{M} \mathrm{D}, \mathrm{L}-\mathrm{AP}-5$, and $1 \mu \mathrm{M}$ CGP. N0-711 was applied at $2.5 \mu \mathrm{m}$, and bic was applied at $10 \mu \mathrm{M}$. B, Bar graph showing the duration (defined as time of decay to $30 \%$ from the instantaneous level) of the slow current at the time of the last stimulus pulse and the mean total charge transfer after the last pulse ( $n=6$ recordings). Events occurring $>4$ min after the start of N0-711 application were included in the quantification. C, Voltage-clamp recordings showing currents evoked by a train of stimuli (30 pulses, $10 \mathrm{~Hz}$; horizontal bar) in a solution containing $0.5 \mathrm{~mm} \mathrm{Ca}{ }^{2+}$ plus $5 \mathrm{~mm} \mathrm{Mg}^{2+}$ (top trace), with $2.5 \mu \mathrm{m}$ N0-711 (middle trace), and subsequent addition of $1 \mu \mathrm{m}$ TTX (bottom trace).

dicating that they are dependent on action potential firing and not on nonvesicular GABA release (cf. Demarque et al., 2002).

Next, we investigated whether GABA uptake would be involved in endogenous network activity, which is characteristic of the neonate hippocampus (see Introduction and Ben-Ari et al., 1989; Leinekugel et al., 2002). In the absence of the glutamateand $\mathrm{GABA}_{\mathrm{B}}$-receptor blockers, voltage-clamp recordings showed spontaneous bursts of outwardly directed GABAergic currents (Fig. 2A) that will be called GDPs (Ben-Ari et al., 1989). The mean duration (time between currents at $10 \%$ of the peak amplitude during event onset and decay) of these events was $620 \pm 60$ msec, and the total charge transfer was $69 \pm 21 \mathrm{pC}(n=6)$ (Fig. $2 B)$. Bath application of $2.5 \mu \mathrm{M} \mathrm{NO}-711$ increased GDP duration to $230 \pm 27 \%(p=0.005)$ and total charge transfer to $187 \pm 20 \%$ $(p=0.007)$ of the control level $(n=6)$ (Fig. $2 A, B)$. Blocking GAT-1 preferentially exerted its effect on the decaying phase of GDPs. The $90-10 \%$ decay time in NO-711 was enhanced to 
A
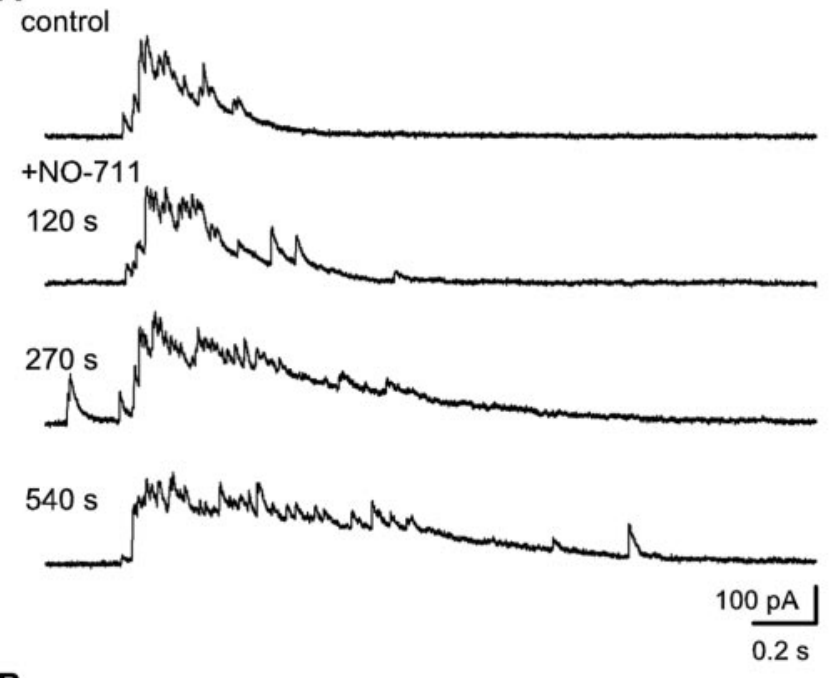

B

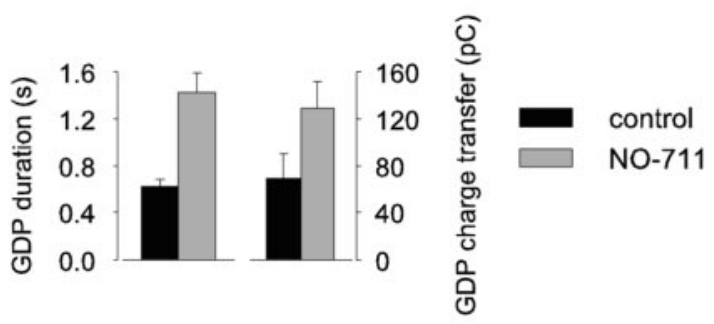

C

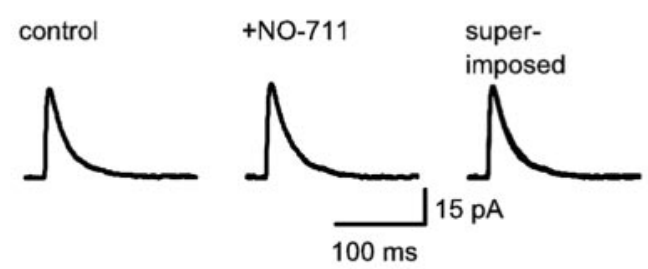

D

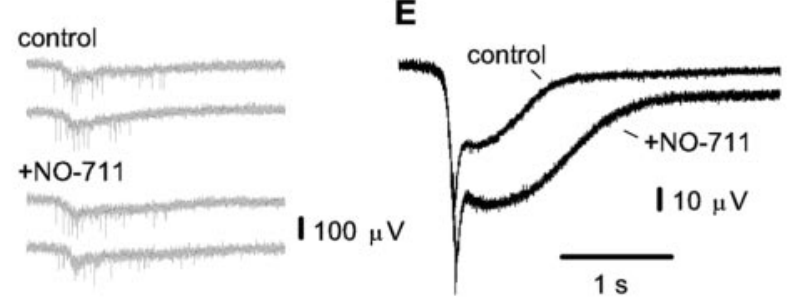

Figure 2. GAT-1 regulates GABAergic transmission during GDPs. $A$, Voltage-clamp recordings showing spontaneous bursts of $\mathrm{GABA}_{A} \mathrm{R}$-mediated outward currents under standard conditions and the effect of $2.5 \mu \mathrm{m}$ N0-711. B, Bar graph showing GDP duration and the associated total charge transfer from six recordings. Events occurring $>4$ min after the start of N0-711 application were included in the quantification. C, N0-711 has no detectable effect on sIPSCs. Averaged recordings of 46 sIPSCs in control and 36 recordings in the presence of $2.5 \mu \mathrm{m}$ N0-711. $D$, Specimen traces showing spontaneous fp responses associated with GDPs in control and in the presence of $2.5 \mu \mathrm{m}$ N0-711. E, Averaged recordings of 33 spontaneous fp responses both in control and in the presence of $2.5 \mu \mathrm{m}$ N0-711

$237 \pm 25 \%$ versus control $(462 \pm 76$ msec; $p=0.003)$, whereas the $10-90 \%$ rise time was not statistically different from control.

In accordance with previous results in mature tissue (Thompson and Gähwiler, 1992; Nusser and Mody, 2002; Overstreet and Westbrook, 2003), $2.5 \mu \mathrm{M}$ NO-711 had no statistically significant effect on the mean total charge transfer $(1.1 \pm 0.07 \mathrm{pC}$ in control and $1.1 \pm 0.02 \mathrm{pC}$ in NO-711), peak amplitude $(37 \pm 5.6 \mathrm{pA}$ in control and $33 \pm 4.8 \mathrm{pA}$ in NO-711), or weighted decay $\tau(23.8 \pm$
$2.9 \mathrm{msec}$ in control and $27 \pm 4.2 \mathrm{msec}$ in NO-711) of averaged sIPSCs (330 and 325 single sIPSCs in control and in the presence of NO-711, respectively, from six recordings) (Fig. 2C). The average sIPSC frequency during inter-GDP intervals under control conditions $(2.5 \pm 0.8 \mathrm{~Hz})$ was not different from that seen in the presence of $2.5 \mu \mathrm{M} \mathrm{NO}-711(2.0 \pm 0.6 \mathrm{~Hz})$.

In agreement with the intracellular recordings (Fig. $2 \mathrm{~A}$ ), 2.5 $\mu \mathrm{M}$ NO-711 had no detectable effect on the initial fast phase of the spontaneous fp responses associated with GDPs, but it enhanced the mean amplitude of their slower phase by a factor of $1.3 \pm 0.1$ (28 $\pm 7 \mu \mathrm{V}$ in control; $p=0.05 ; 336$ and 193 single fp GDPs in control and in the presence of NO-711, respectively, from five recordings) (Fig. $2 D, E$ ). In addition, a marked increase in the duration of the GDP-associated fp responses was seen, with a mean time to $90 \%$ decay of $4.0 \pm 1.3$ and $2.3 \pm 0.9 \mathrm{sec}$ in the presence and absence of NO-711, respectively $(p=0.03)$. However, the increase in the field response was not accompanied by any clear change in the rate of unit spiking (Fig. 2D). Finally, the field recordings indicated a decrease in GDP frequency in NO711 to $51 \pm 16 \%$ of the value in control $(0.022 \pm 0.006 \mathrm{~Hz} ; p=$ $0.036)$. The decrease in GDP frequency was not studied further, but it may well reflect an increase in the time needed to restore neuronal $\mathrm{Cl}^{-}$gradients after the enhanced dissipation (and a consequent reduction in the driving force for excitatory GABA responses) that is likely to take place during the NO-711mediated increase in GDP amplitude and duration (cf. Chub and O’Donovan, 2001).

\section{Discussion}

The present data indicate that GAT-1 modulates synaptic transmission under physiological conditions in the early postnatal rat hippocampus. In particular, GAT-1 operation limits the duration of extracellular GABA transients during synchronous pyramidal and interneuronal firing associated with GDPs, which constitute the main type of electrophysiological activity in the immature hippocampus both in vitro and in vivo (Ben-Ari et al., 1989; Leinekugel et al., 2002).

In the work by Draguhn and Heinemann (1996), IPSCs elicited by single stimuli in the early postnatal dentate gyrus were not affected by the GABA uptake blocker tiagabine. The authors suggested that the relatively large extracellular space characteristic of immature brain tissue, permitting effective net diffusion, is responsible for clearing GABA from synaptic clefts. Our results are not in direct contradiction with this idea. However, a dramatic effect of blocking GABA uptake was observed after more intense synaptic activity.

In mature neurons, a decrease in peak IPSC amplitude has been observed after inhibition of GAT- 1 and has been explained by receptor desensitization (Overstreet et al., 2000). The lack of a statistically significant effect with NO-711 on sIPSC amplitude in the present study is in agreement with the smaller sensitivity of $\mathrm{GABA}_{\mathrm{A}}$ receptors in immature neurons to desensitization (Cherubini et al., 1990).

The GAT-1 protein is primarily located in presynaptic GABAergic terminals (Minelli et al., 1995), but during early postnatal development of the rat hippocampus, it is seen also in somata of interneurons (Yan et al., 1997). In addition, GAT-1 mRNA has been detected in principal neurons (Frahm and Draguhn, 2001). The stoichiometry of GAT-1 in the uptake mode has been suggested to be $1 \mathrm{GABA}: 2 \mathrm{Na}^{+}: 1 \mathrm{Cl}^{-}$(Cammack et al., 1994). Although the exact ionic milieu surrounding GAT-1 is not known, the relatively high intracellular chloride concentration of immature neurons (Kakazu et al., 1999; Kuner and Augustine, 
2000; Payne et al., 2003) could potentially inhibit the uptake mode. However, we observed an increase in the $G_{A B A} R-$ mediated currents in response to GAT-1 block, which suggests that under physiological conditions, it operates in net uptake mode in immature tissue as well.

The results as a whole support the idea that GAT-1 prevents GABA spillover to extrasynaptic sites and cross-talk between synapses (Thompson and Gähwiler, 1992; Isaacson et al., 1993; Barbour and Hausser, 1997) during intense interneuronal firing that is associated with early network activity in the immature hippocampus, and probably in other brain structures as well. Given the key role of GABA in the generation of immature-type spontaneous network activity (Owens and Kriegstein, 2002), the dramatic influence of blocking GAT-1 on GDPs suggests that GABA uptake may be intimately involved in activity-dependent neuronal wiring. More specifically, GABA uptake might promote independence of GABAergic synapses (Overstreet and Westbrook, 2003 ) in developing brain structures.

\section{References}

Barbour B, Hausser M (1997) Intersynaptic diffusion of neurotransmitter. Trends Neurosci 20:377-384.

Ben-Ari Y, Cherubini E, Corradetti R, Gaiarsa JL (1989) Giant synaptic potentials in immature rat CA3 hippocampal neurones. J Physiol (Lond) 416:303-325.

Berry MS, Pentreath VW (1976) Criteria for distinguishing between monosynaptic and polysynaptic transmission. Brain Res 105:1-20.

Caillard O, McLean HA, Ben Ari Y, Gaiarsa JL (1998) Ontogenesis of presynaptic GABAB receptor-mediated inhibition in the CA3 region of the rat hippocampus. J Neurophysiol 79:1341-1348.

Cammack JN, Rakhilin SV, Schwartz EA (1994) A GABA transporter operates asymmetrically and with variable stoichiometry. Neuron 13:949-960.

Cherubini E, Rovira C, Gaiarsa JL, Corradetti R, Ben Ari Y (1990) GABA mediated excitation in immature rat CA3 hippocampal neurons. Int J Dev Neurosci 8:481-490.

Chub N, O'Donovan MJ (2001) Post-episode depression of GABAergic transmission in spinal neurons of the chick embryo. J Neurophysiol 85:2166-2176.

Demarque M, Represa A, Becq H, Khalilov I, Ben Ari Y, Aniksztejn L (2002) Paracrine intercellular communication by a $\mathrm{Ca}^{2+}$ - and SNAREindependent release of GABA and glutamate prior to synapse formation. Neuron 36:1051-1061.

Draguhn A, Heinemann U (1996) Different mechanisms regulate IPSC kinetics in early postnatal and juvenile hippocampal granule cells. J Neurophysiol 76:3983-3993.

Feller MB (1999) Spontaneous correlated activity in developing neural circuits. Neuron 22:653-656.

Frahm C, Draguhn A (2001) GAD and GABA transporter (GAT-1) mRNA expression in the developing rat hippocampus. Brain Res Dev Brain Res 132:1-13.

Frahm C, Engel D, Draguhn A (2001) Efficacy of background GABA uptake in rat hippocampal slices. NeuroReport 12:1593-1596.

Guastella J, Nelson N, Nelson H, Czyzyk L, Keynan S, Miedel MC, Davidson N, Lester HA, Kanner BI (1990) Cloning and expression of a rat brain GABA transporter. Science 249:1303-1306.
Isaacson JS, Solís JM, Nicoll RA (1993) Local and diffuse synaptic actions of GABA in the hippocampus. Neuron 10:165-175.

Jensen K, Chiu CS, Sokolova I, Lester HA, Mody I (2003) GABA transporter-1 (GAT1)-deficient mice: differential tonic activation of GABAA versus GABAB receptors in the hippocampus. J Neurophysiol 90:2690-2701.

Kaila K, Voipio J, Paalasmaa P, Pasternack M, Deisz RA (1993) The role of bicarbonate in GABAA receptor-mediated IPSPs of rat neocortical neurones. J Physiol (Lond) 464:273-289.

Kakazu Y, Akaike N, Komiyama S, Nabekura J (1999) Regulation of intracellular chloride by cotransporters in developing lateral superior olive neurons. J Neurosci 19:2843-2851.

Katz LC, Crowley JC (2002) Development of cortical circuits: lessons from ocular dominance columns. Nat Rev Neurosci 3:34-42.

Kuner T, Augustine GJ (2000) A genetically encoded ratiometric indicator for chloride: capturing chloride transients in cultured hippocampal neurons. Neuron 27:447-459.

Leinekugel X, Khazipov R, Cannon R, Hirase H, Ben Ari Y, Buzsaki G (2002) Correlated bursts of activity in the neonatal hippocampus in vivo. Science 296:2049-2052.

Minelli A, Brecha NC, Karschin C, DeBiasi S, Conti F (1995) GAT-1, a high-affinity GABA plasma membrane transporter, is localized to neurons and astroglia in the cerebral cortex. J Neurosci 15:7734-7746.

Nusser Z, Mody I (2002) Selective modulation of tonic and phasic inhibitions in dentate gyrus granule cells. J Neurophysiol 87:2624-2628.

Overstreet LS, Westbrook GL (2003) Synapse density regulates independence at unitary inhibitory synapses. J Neurosci 23:2618-2626.

Overstreet LS, Jones MV, Westbrook GL (2000) Slow desensitization regulates the availability of synaptic $\mathrm{GABA}_{\mathrm{A}}$ receptors. J Neurosci 20:7914-7921.

Owens DF, Kriegstein AR (2002) Is there more to GABA than synaptic inhibition? Nat Rev Neurosci 3:715-727.

Payne JA, Rivera C, Voipio J, Kaila K (2003) Cation-chloride cotransporters in neuronal communication, development and trauma. Trends Neurosci 26:199-206.

Penn AA, Shatz CJ (1999) Brain waves and brain wiring: the role of endogenous and sensory-driven neural activity in development. Pediatr Res 45:447-458.

Roepstorff A, Lambert JD (1994) Factors contributing to the decay of the stimulus-evoked IPSC in rat hippocampal CA1 neurons. J Neurophysiol 72:2911-2926.

Sabau A, Frahm C, Pfeiffer M, Breustedt J, Piechotta A, Numberger M, Engel D, Heinemann U, Draguhn A (1999) Age-dependence of the anticonvulsant effects of the GABA uptake inhibitor tiagabine in vitro. Eur J Pharmacol 383:259-266.

Semyanov A, Walker MC, Kullmann DM (2003) GABA uptake regulates cortical excitability via cell type-specific tonic inhibition. Nat Neurosci 6:484-490.

Stuart GJ, Dodt HU, Sakmann B (1993) Patch-clamp recordings from the soma and dendrites of neurons in brain slices using infrared video microscopy. Pflügers Arch 423:511-518.

Thompson SM, Gähwiler BH (1992) Effects of the GABA uptake inhibitor tiagabine on inhibitory synaptic potentials in rat hippocampal slice cultures. J Neurophysiol 67:1698-1701.

Yan XX, Cariaga WA, Ribak CE (1997) Immunoreactivity for GABA plasma membrane transporter, GAT-1, in the developing rat cerebral cortex: transient presence in the somata of neocortical and hippocampal neurons. Brain Res Dev Brain Res 99:1-19. 